\title{
Template for documenting and reporting data in physician-staffed pre-hospital services: a consensus-based update
}

\author{
Kristin Tønsager ${ }^{1,2,3^{*}}$ D, Andreas Jørstad Krüger ${ }^{1,4}$, Kjetil Gorseth Ringdal5 ${ }^{5,6}$, Marius Rehn ${ }^{1,3,7}$ and the P-EMS \\ Template Collaborating Group
}

\begin{abstract}
Background: Physician-staffed emergency medical services (p-EMS) are resource demanding, and research is needed to evaluate any potential effects of p-EMS. Templates, designed through expert agreement, are valuable and feasible, but they need to be updated on a regular basis due to developments in available equipment and treatment options. In 2011, a consensus-based template documenting and reporting data in p-EMS was published. We aimed to revise and update the template for documenting and reporting in p-EMS.

Methods: A Delphi method was applied to achieve a consensus from a panel of selected European experts. The experts were blinded to each other until a consensus was reached, and all responses were anonymized. The experts were asked to propose variables within five predefined sections. There was also an optional sixth section for variables that did not fit into the pre-defined sections. Experts were asked to review and rate all variables from 1 (totally disagree) to 5 (totally agree) based on relevance, and consensus was defined as variables rated $\geq 4$ by more than $70 \%$ of the experts.
\end{abstract}

Results: Eleven experts participated. The experts generated 194 unique variables in the first round. After five rounds, a consensus was reached. The updated dataset was an expanded version of the original dataset and the template was expanded from 45 to 73 main variables. The experts approved the final version of the template.

Conclusions: Using a Delphi method, we have updated the template for documenting and reporting in p-EMS. We recommend implementing the dataset for standard reporting in p-EMS.

Keywords: Documentation, Data collection, Pre-hospital, Physician, Emergency medical services, Consensus, Air ambulances, Quality of health care

\section{Background}

Physician-staffed emergency medical services (p-EMS) are common in European countries, and they provide highly specialized, goal-directed therapy. Pre-hospital physicians have the potential to restore adequate flow and physiology in severely sick or injured patients, but the subject remains

\footnotetext{
* Correspondence: kristin.tonsager@norskluftambulanse.no

'Department of Research, The Norwegian Air Ambulance Foundation, Post box 414, Sentrum, N-0103, Oslo, Norway

${ }^{2}$ Department of Anaesthesiology and Intensive Care, Stavanger University Hospital, Stavanger, Norway

Full list of author information is available at the end of the article
}

debated [1-6]. P-EMS are resource demanding compared with standard paramedic-staffed services [7], and more research is needed to evaluate any potential effects of p-EMS $[1,8,9]$. High-quality research relies on data quality and uniform documentation is essential to ensure reliable and valid data. Currently, p-EMS data are low quality, and the lack of systematic documentation complicates comparison, creating a barrier for high-quality outcome research [10].

In 2011, a consensus-based template for documenting and reporting data in p-EMS was published [7]. Templates for uniform documentation may facilitate international 
multi-centre studies, thereby increasing the quality of evidence [11]. Such templates, designed through expert agreement, are valuable and feasible, but they need to be updated on a regular basis due to developments in available equipment and treatment options [12-15]. The pEMS template has been incorporated for daily use in Finland, but it has not yet been implemented in other European countries. A recent study concluded that the published template is feasible for use in p-EMS and that a large amount of data may be captured, facilitating collaborative research [16]. However, the feasibility study revealed areas for improvement of the template. To make the template even more relevant, further revisions should be made.

The aim of this study was to revise and update the template for documenting and reporting in p-EMS through expert consensus [7] using the Delphi method.

\section{Methods}

\section{The experts}

No exact criterion exists concerning selection of participants for a Delphi study.

Many European countries share similarities with regards to infrastructure, socio-political system and health care services, favouring research collaboration [17]. Representatives from European p-EMS were invited to join an expert panel using the same inclusion criteria as the original template:

1. Clinical experience by working in p-EMS to ensure personal insight into the operative and medical characteristics of advanced pre-hospital care.

2. Scientific and/or substantial leadership responsibilities in pre-hospital care to ensure competency in research methods and governance of pre-hospital emergency systems.

3. Ability to communicate in English.

The experts were identified via the European Prehospital Research Alliance (EUPHOREA) network. The EUPHOREA network consists of representatives from pEMS throughout central Europe, UK and Scandinavia. Experts were invited via e-mail. Non-responders were reminded via e-mail. For all rounds non-responders were reminded twice per e-mail.

\section{The Delphi method}

A Delphi technique was applied to achieve a consensus from a panel of selected experts interacting via e-mail. No physical meetings were held. A research coordinator interacted with the participants, administered questionnaires and collected the responses until a consensus was reached. The experts were blinded to each other until an agreement was reached. All responses were anonymized.
The Delphi process ran from Feb. 19 to Oct. 1, 2019. The final dataset was approved by all experts.

\section{Objectives for each round of the Delphi process}

The experts were asked to propose variables within each of five predefined sections:

\section{Fixed system variables}

Variables describing how the p-EMS is organized, competence in the p-EMS team and its operational capacities (e.g., dispatch criteria, population, mission case-mix and equipment utilized by the services). These data do not change between missions and are considered fixed.

\section{Event operational descriptors}

Variables documenting the mission context (e.g., data on logistics, type of dispatch, time variables and mission type).

\section{Patient descriptors}

Variables documenting patient state (e.g., age, gender, comorbidity, patient physiology and medical complaint).

\section{Process mapping variables}

Variables documenting diagnostic and therapeutic procedures (e.g., monitoring, medication, airway devices used, etc.) performed during the period of p-EMS care.

\section{Outcome and quality indicators}

Variables describing patient outcome and quality.

There was also an optional sixth section for proposals of variables that did not fit into one of the pre-defined sections.

\section{Round I}

Each expert suggested 10 variables considered to be most important for routine documentation in p-EMS within each of the five predefined sections.

\section{Round II}

The results from the first round were structured in a worksheet (Excel for Mac, version 16.31, 2019 Microsoft). Duplicate suggestions were removed before the variables were returned to the experts. Variables from the original template were included if not suggested by the experts. Experts were asked to review and rate all variables from 1 (totally disagree) to 5 (totally agree) based on relevance.

\section{Round III}

Variables rated $\geq 4$ by more than $70 \%$ of the experts were included in the template draft and presented to the experts $[18,19]$. In addition, the experts received a number of questions pertaining to the wording of questions, 
consent to delete some questions because of overlap, relevance of alternatives under a main question, and whether there should be a free-text field for addressing key lessons. Furthermore, they were instructed to provide comments and grade the variables as either compulsory or optional. Later, the experts were asked to suggest the frequency of variable reporting (for each mission, monthly or annually). Variables rated $\geq 4$ by less than $50 \%$ of the experts were excluded. Variables rated $\geq 4$ by more than $50 \%$ of the experts were summarized and rerated by the experts. If more than $70 \%$ of the experts rated a variable $\geq 4$ in this second round, the variable was included in the final template.

\section{Round IV}

After summarizing the feedback from round III, the list of variables achieving consensus, accompanying comments, and further questions were distributed to the experts. All variables were numbered. This round provided an opportunity for the experts to revise their judgements and combine similar variables.

\section{Round V}

Feedback from round IV was summarized into a final version of the template and sent to the experts to elicit any objections and/or to give final approval of the template for routine reporting in p-EMS.

The study was drafted according to the Standards for Reporting Qualitative Research (SRQR) [20].

\section{Results}

\section{The experts}

Thirty experts were invited to join the consensus process and 15 agreed to participate. Eleven experts responded in the first Delphi round, ten responded in the second round and nine responded in the last three rounds.

\section{Round I}

The experts suggested 194 unique variables in the first round (Fig. 1). All variables from the original template were among the suggested variables.

\section{Round II}

The experts rated the variables suggested in round I from 1 (totally disagree) to 5 (totally agree) based on relevance. A total of 68 main variables (24 fixed system variables, 10 event operational descriptors, 15 patient descriptors, 10 process mapping variables, 9 outcome and quality indicators and no other variables) were rated $\geq 4$ by more than $70 \%$ of the experts and included in the preliminary template. Thirty-five main variables and 32 sub-variables were rated $<4$ by $50-70 \%$ of the experts. Ninety-one variables were rated $\geq 4$ by less than $50 \%$ of the experts and were excluded.

\section{Round III}

The preliminary template was presented to the experts. Additionally, the experts rated the 35 main variables and 32 sub-variables that were initially rated $\geq 4$ by $50-70 \%$ once more. Five more main variables and 9 sub-variables were included after this second rating. In total, 73 main variables were included (Fig. 2). The experts agreed that all fixed system variables should be reported annually while all event operational descriptors, patient descriptors, process mapping variables and outcome and quality indicators should be reported after each mission.

\section{Round IV}

The included variables were presented to the experts. After feedback from the experts the wording of variables 1.23.6 and 3.5.6. were changed from "Chest pain, excluding MI" to "Chest pain, MI not confirmed". Variable 3.8.4. "Systolic blood pressure (SBP) not recordable" and 3.10.4. "SpO2 not recordable" were added. Variables 3.13.1. and 3.13.2. were changed to record the VAS score instead of pain as none, moderate or severe and variable 4.6.17. was changed from "Resuscitative endovascular balloon occlusion of the aorta (REBOA)" to "Endovascular Resuscitation (EVR)".

\section{Round V}

The experts approved the final version of the template (Table 1, 2, 3, 4 and 5).

\section{Discussion}

Main findings

Using Delphi methodology, we have updated a template for standard documentation in p-EMS. The new dataset includes new data variables and the template was expanded from 45 to 73 main variables.

\section{Fixed system variables}

Throughout the world, there are large differences between p-EMS [21-23], and fixed system variables are important to analyse any influence of system factors and compare systems [11, 24]. The experts suggested reporting all fixed system variables annually. Furthermore, the experts chose to include two variables related to quality. The reason for including these data in this section is that they describe the quality of the system rather than the quality delivered during each mission.

\section{Event operational descriptors}

There is no consensus in the literature on how to report mission times $[15,25,26]$ and the experts had several suggestions, i.e., exact times (hh:mm), time intervals (dispatch time, on-scene time, etc.) and time reported as year/month/day/hour of event. Response time (time from unit is dispatched to at patient side), on-scene time 


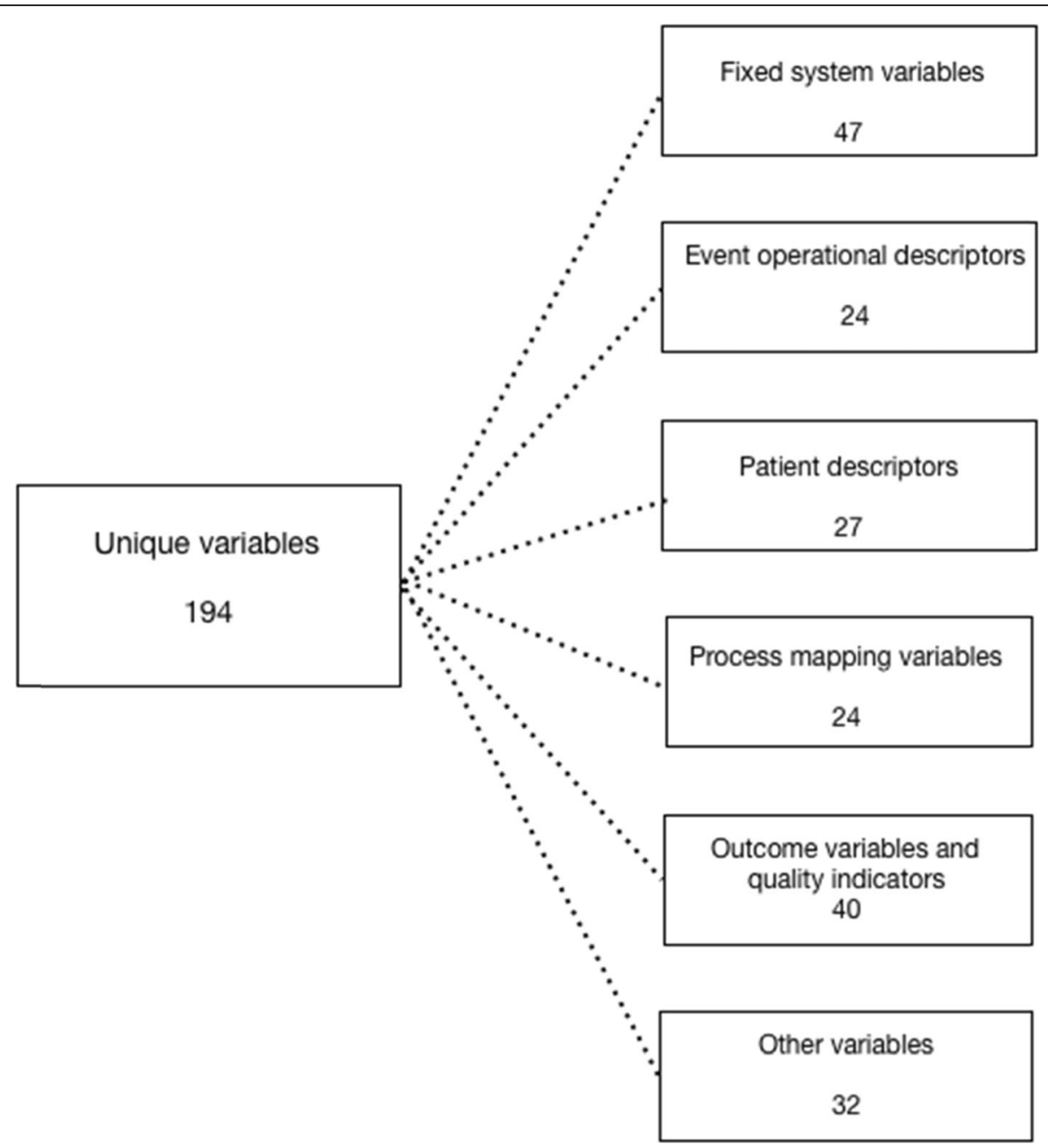

Fig. 1 Suggested variables. Number of suggested variables for the different sections in the first round of the Delphi process

and transport time (from patient leaving the scene to arrival at the hospital) and time from alarm to arrival at the hospital are all reported in various templates. We argue that by reporting exact times, all desired time intervals can easily be calculated; therefore, exact times should be documented.

The time of the event is usually not possible to accurately identify. In trauma, the time of the event will be distinct, but for other diagnoses a clearly defined start time is often missing. The time when a call is received at the emergency medical communication centre (EMCC) is a distinct time that is easy to document, substituting for the time of the event. This was also emphasized by the experts.

P-EMS differ in service profile, and documenting dispatch type is important for benchmarking. Some services are dispatched to all types of emergency missions, whereas others are dispatched to specific types, e.g., trauma. Some services have an extensive workload due to consultation responsibilities and medical direction for ordinary EMS. This may affect availability if work hours are restricted.

\section{Patient descriptors.}

Comorbidity is an important risk adjustment measure, but there is no consensus on comorbidity reporting. The original template for reporting in p-EMS used the American Society of Anesthesiologists Physical Status (ASA-PS) scale in a dichotomized form. However, using full ASA-PS scale has been found to be feasible in pEMS [27], and it is recommended by the experts.

Reporting the present medical problem is crucial for benchmarking. P-EMS have traditionally reported symptoms, but point-of-care diagnostical options are increasingly available, allowing more precise pre-hospital diagnoses [28-30].

The experts recommended reporting physiological data at two different time points: at arrival of the p-EMS 


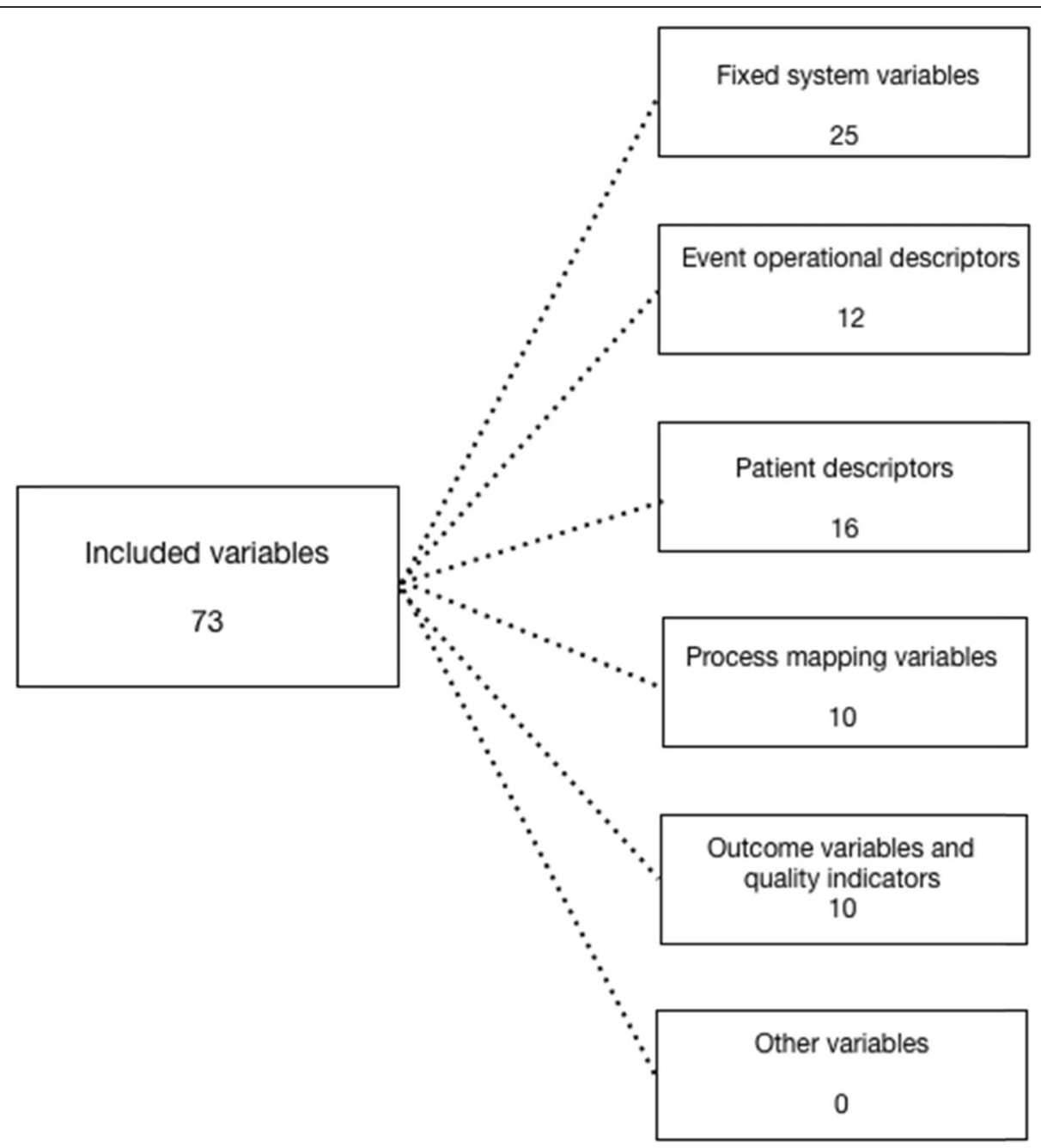

Fig. 2 Included variables. Final number of variables included in the updated template

and at hand-over or the end of patient care. This corresponds with the original template. Reporting data at two different time points allows for monitoring changes in the patient state and may serve as a surrogate measure for p-EMS performance [31]. For SBP and SpO2, the experts also suggest reporting the lowest value measured. Hypotension is an independent predictor of mortality for traumatic brain injury (TBI) patients [32], and reporting the lowest SBP value will capture hypotensive episodes. Further, automated data capture from monitors are increasingly available, enabling continuous measurement of physiological variables. Continuous reporting may capture dynamic changes in patient state, thereby increasing the precision of p-EMS research.

Pain is frequent in the p-EMS patient population, and pain relief is considered good clinical practice [33]. The original template used a three-part scale for reporting pain while the expert group of the revised template suggest reporting pain according to the Visual Analogue Scale (VAS) [34].

\section{Process mapping variables}

The resulting physiological effects of p-EMS treatment and its relation to outcome remains largely unknown in pre-hospital critical care. Such changes in physiology have earlier been difficult to capture but doing so is now more feasible due to technological developments. The experts emphasized this, and as such an expansion of the process mapping section was suggested.

\section{Mission outcome and quality indicators}

To date, there is no agreement on standard quality indicators in p-EMS but Haugland et al. recently developed a set of quality indicators for p-EMS [35]. Several of these indicators are documented in the revised template but under various sections. Additionally, the experts suggested several other contextspecific quality variables related to the individual patient, but these are yet to be validated. 


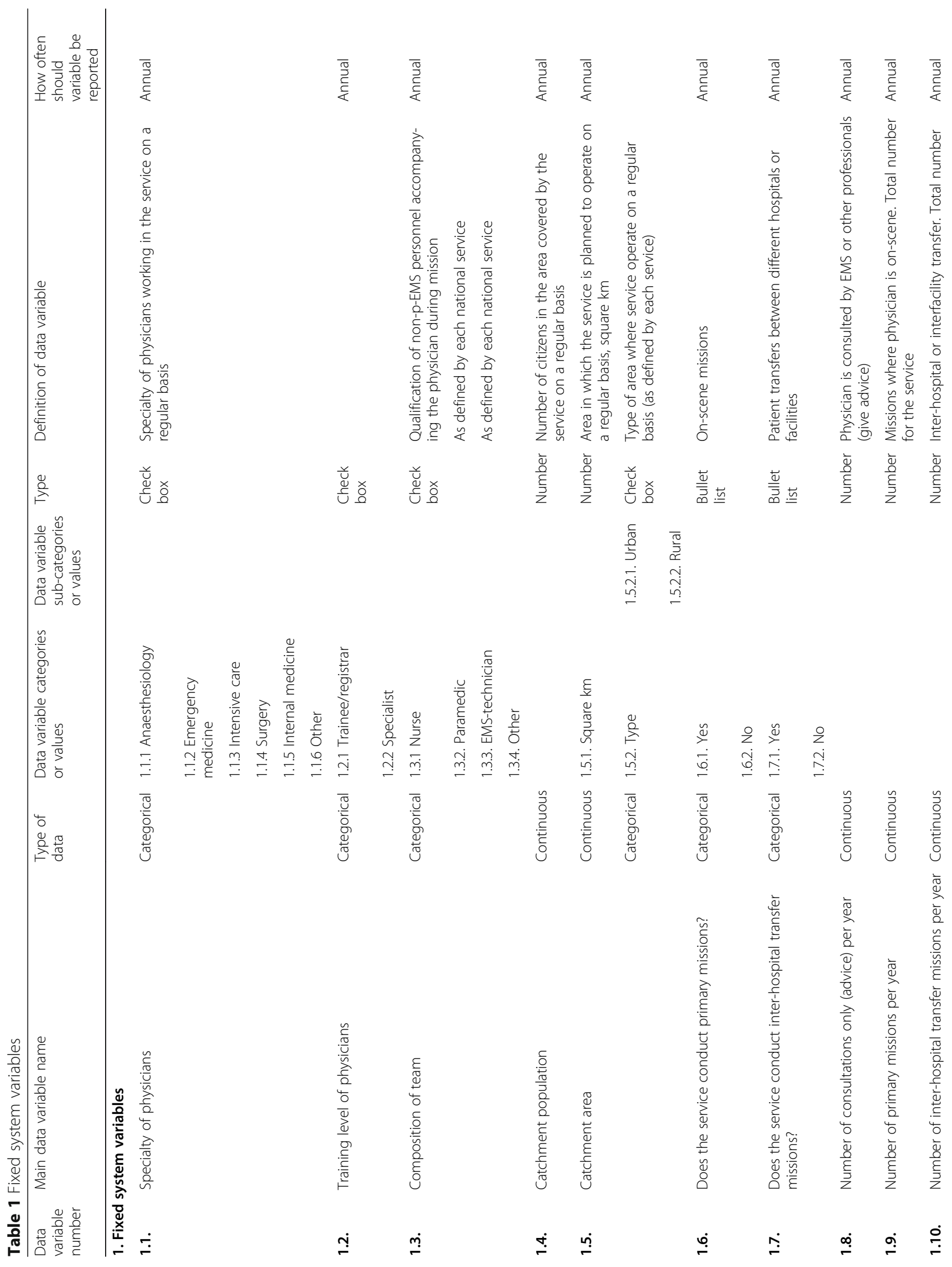




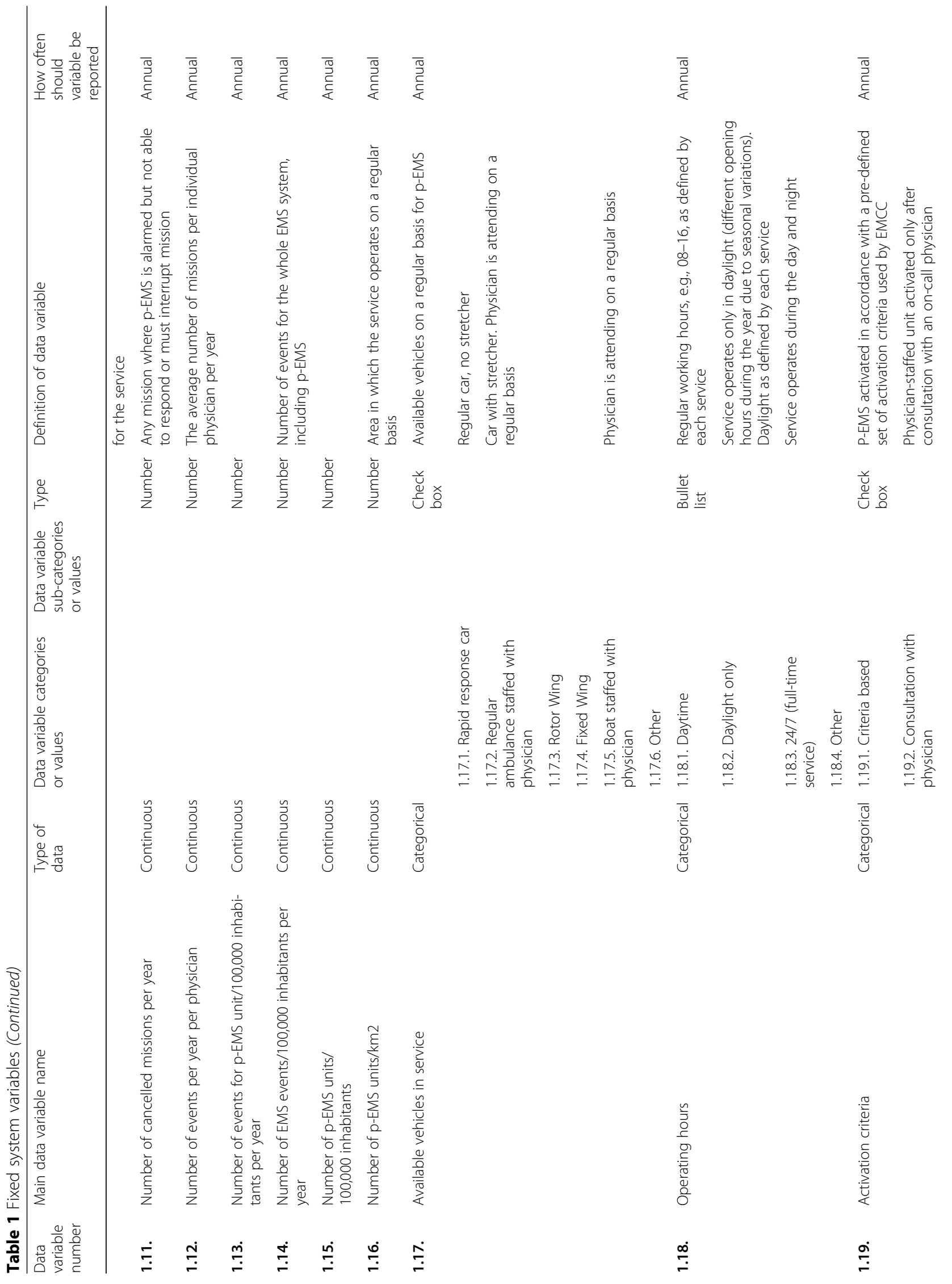


Tønsager et al. Scandinavian Journal of Trauma, Resuscitation and Emergency Medicine

(2020) $28: 25$

Page 8 of 28

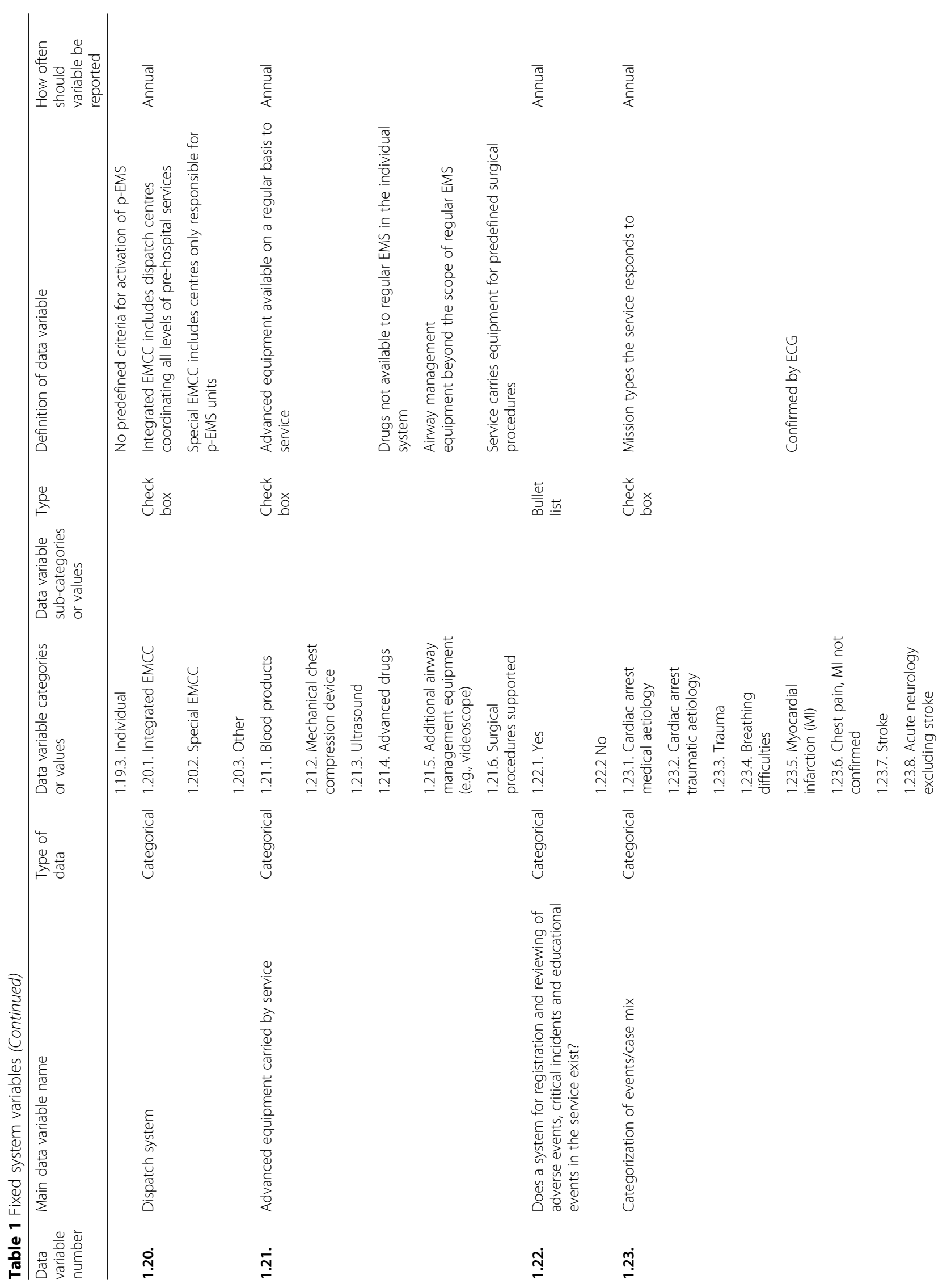




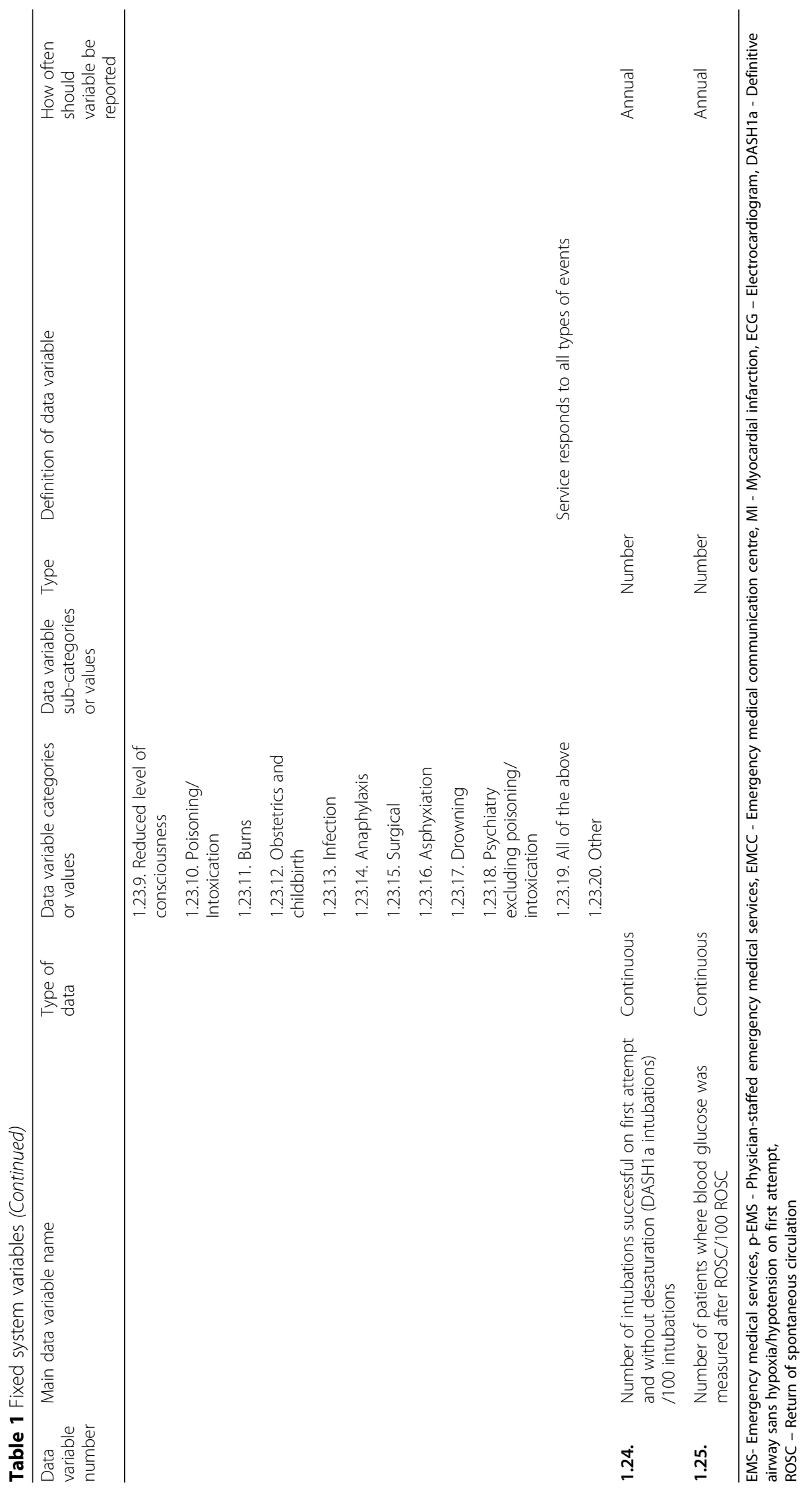




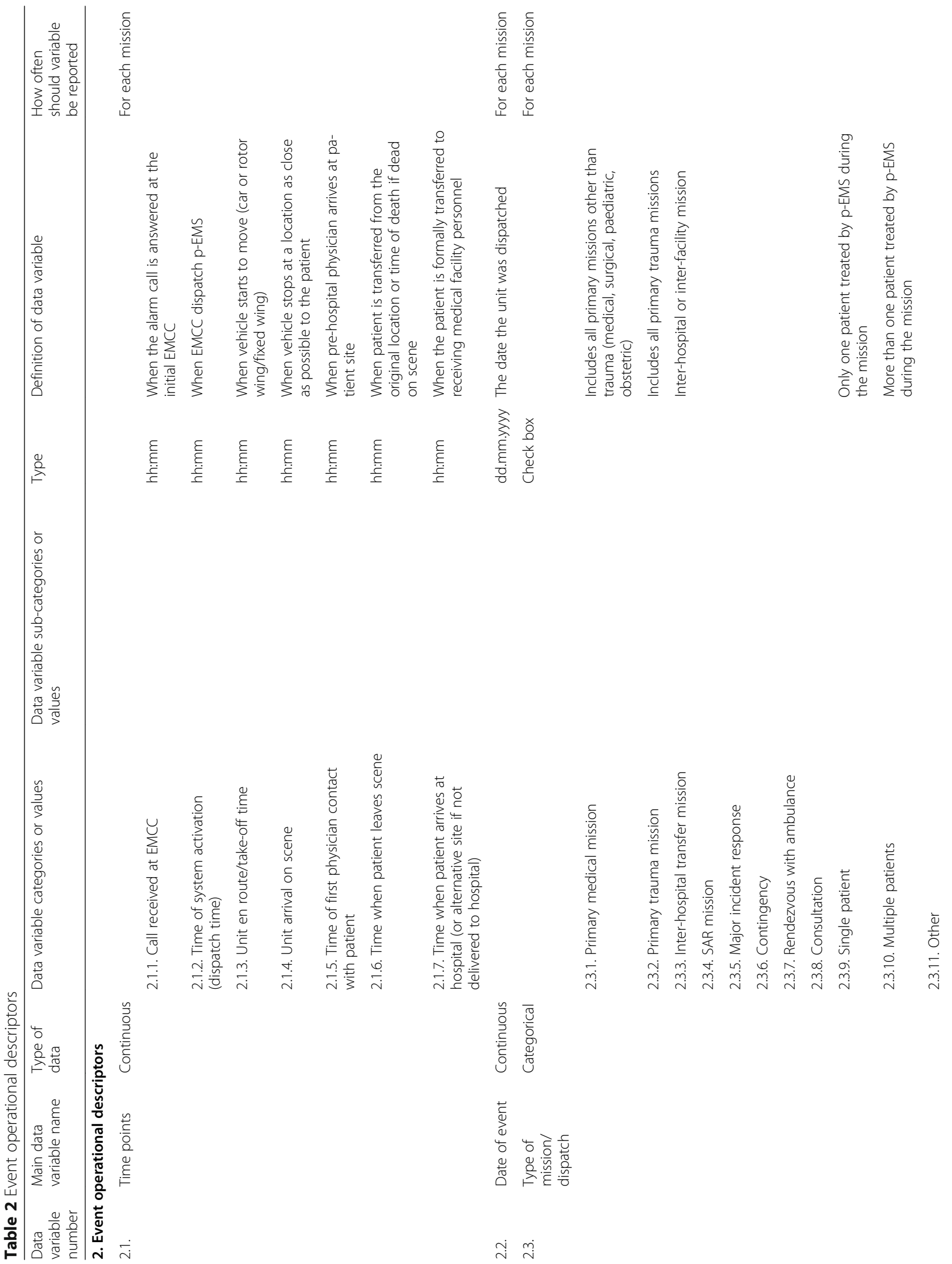




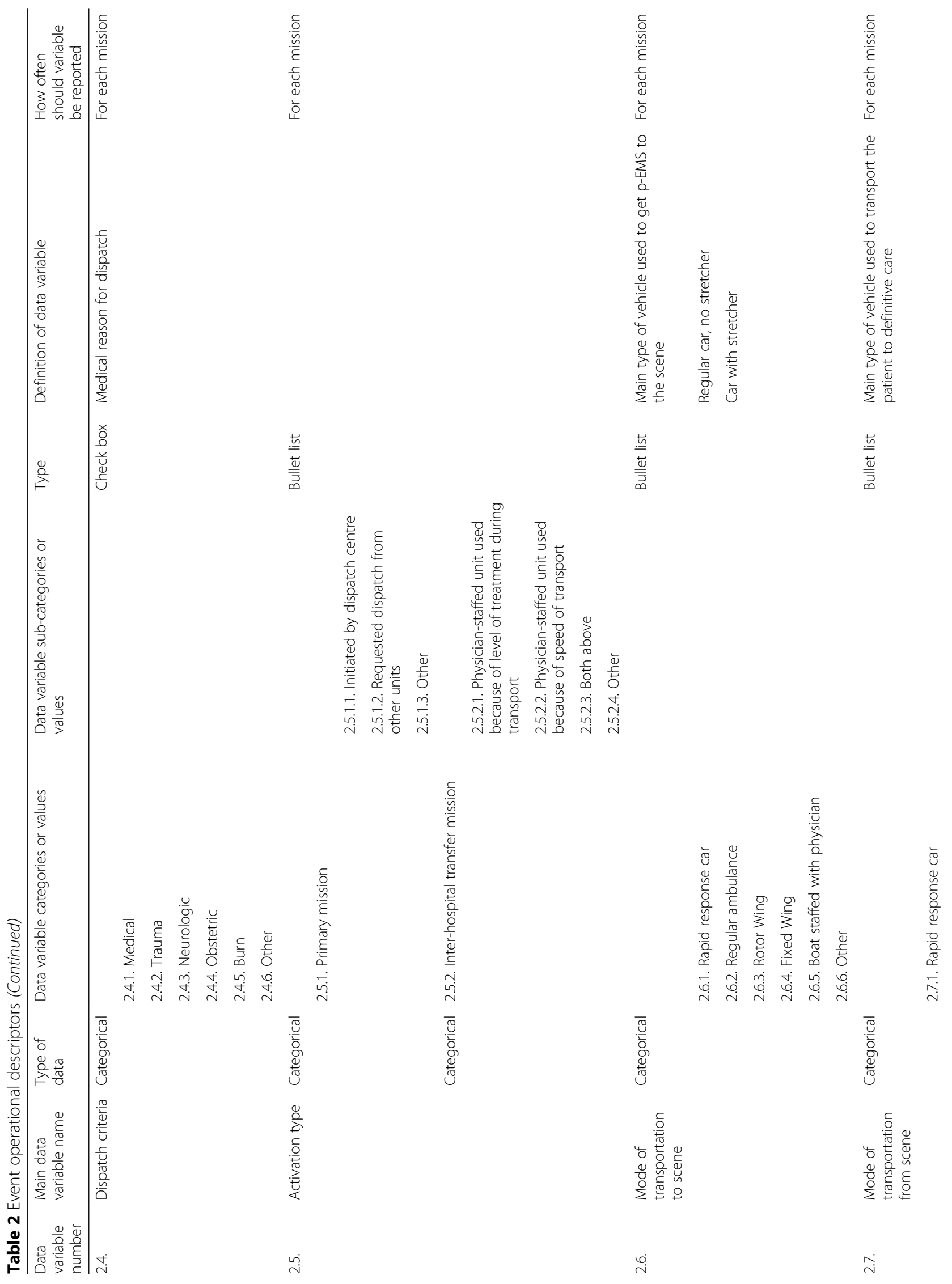




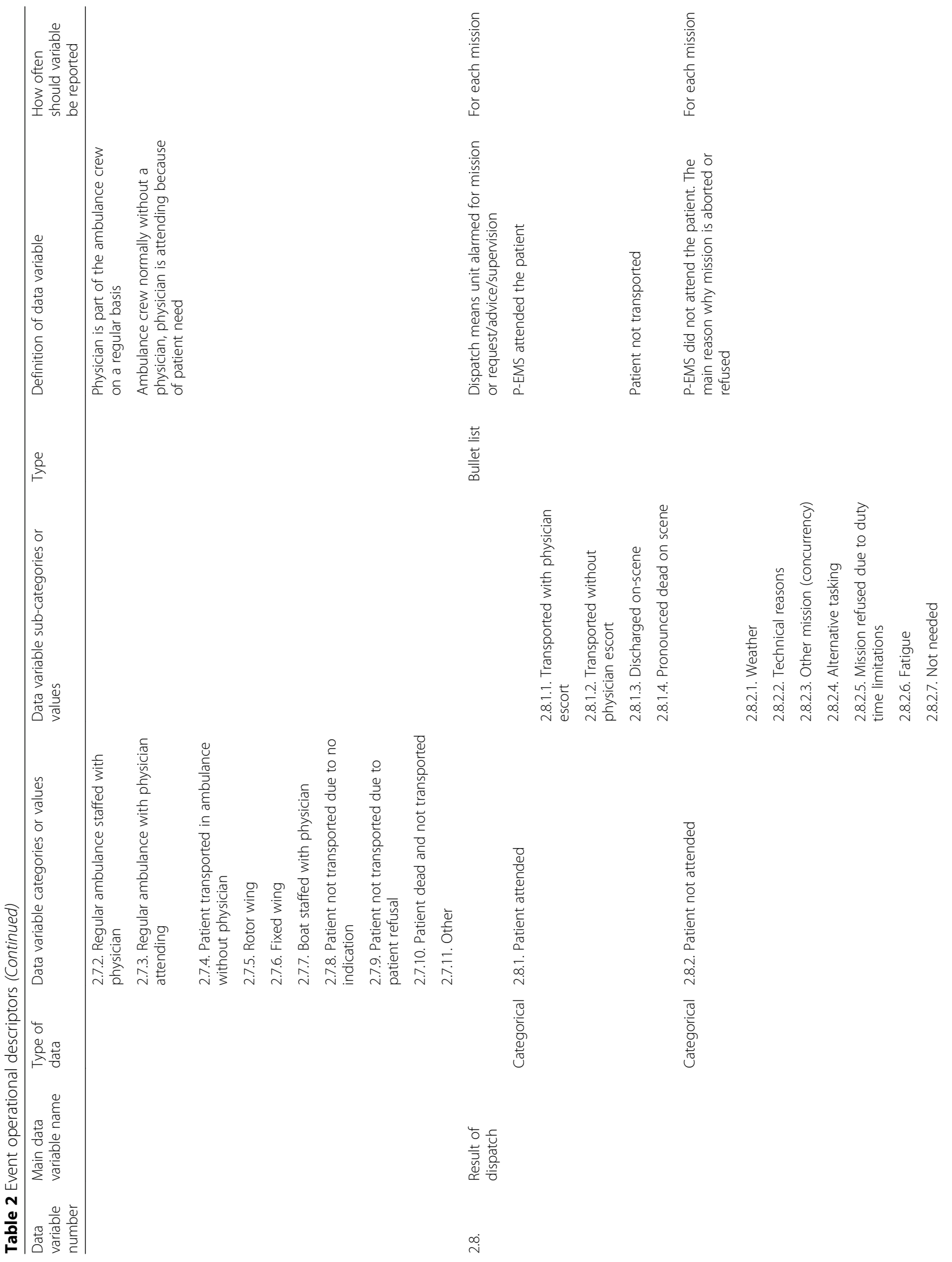




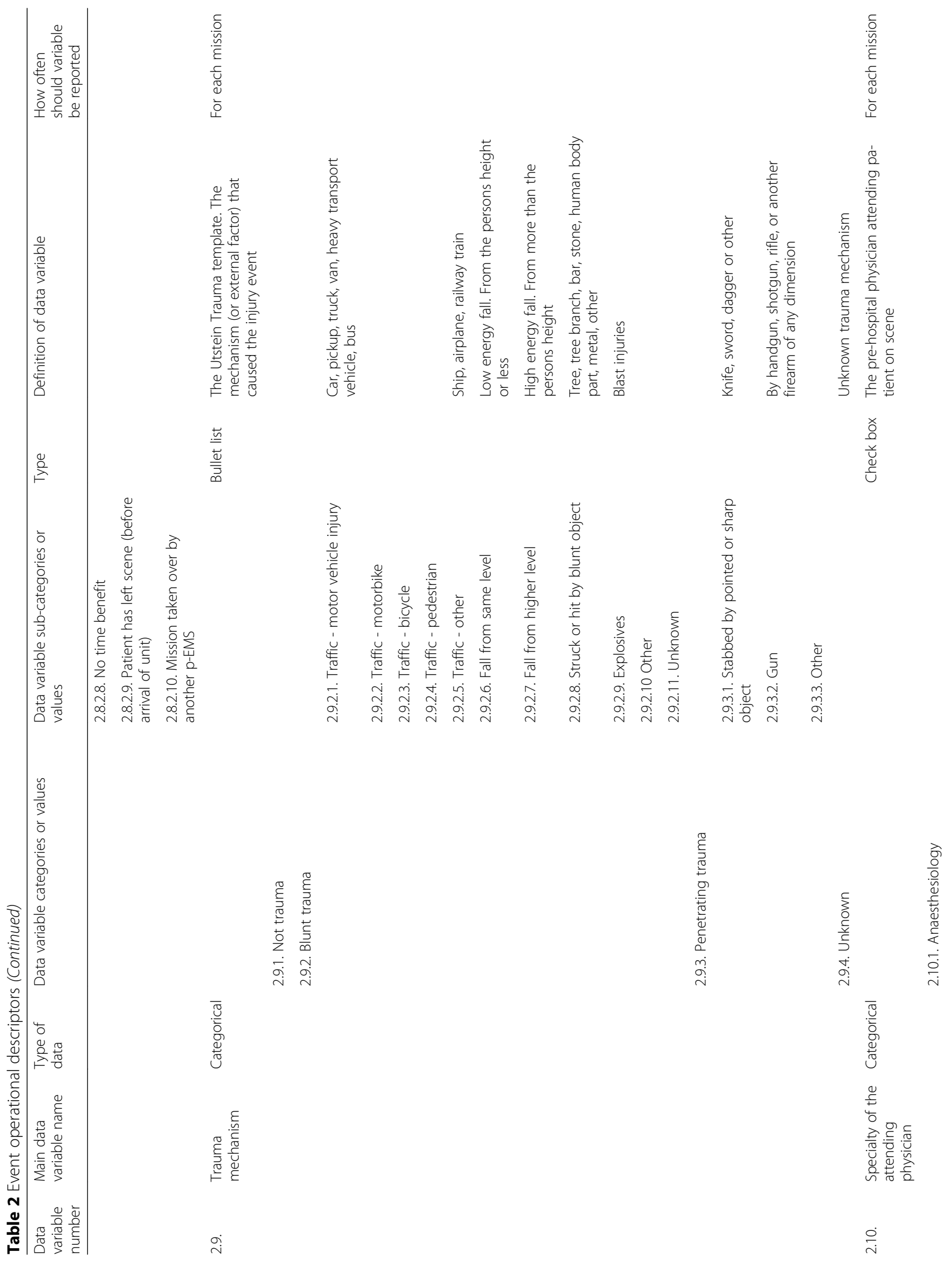









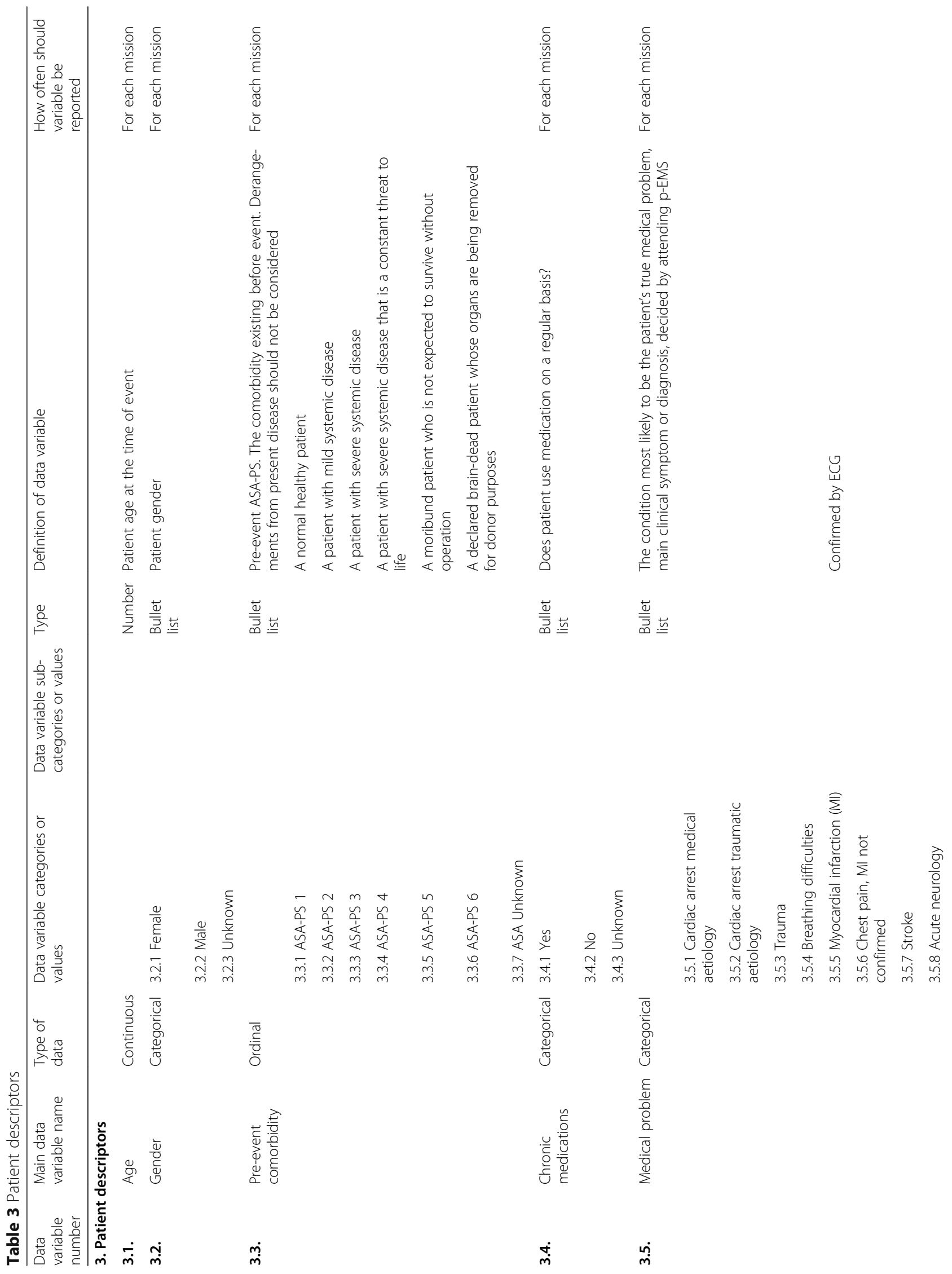




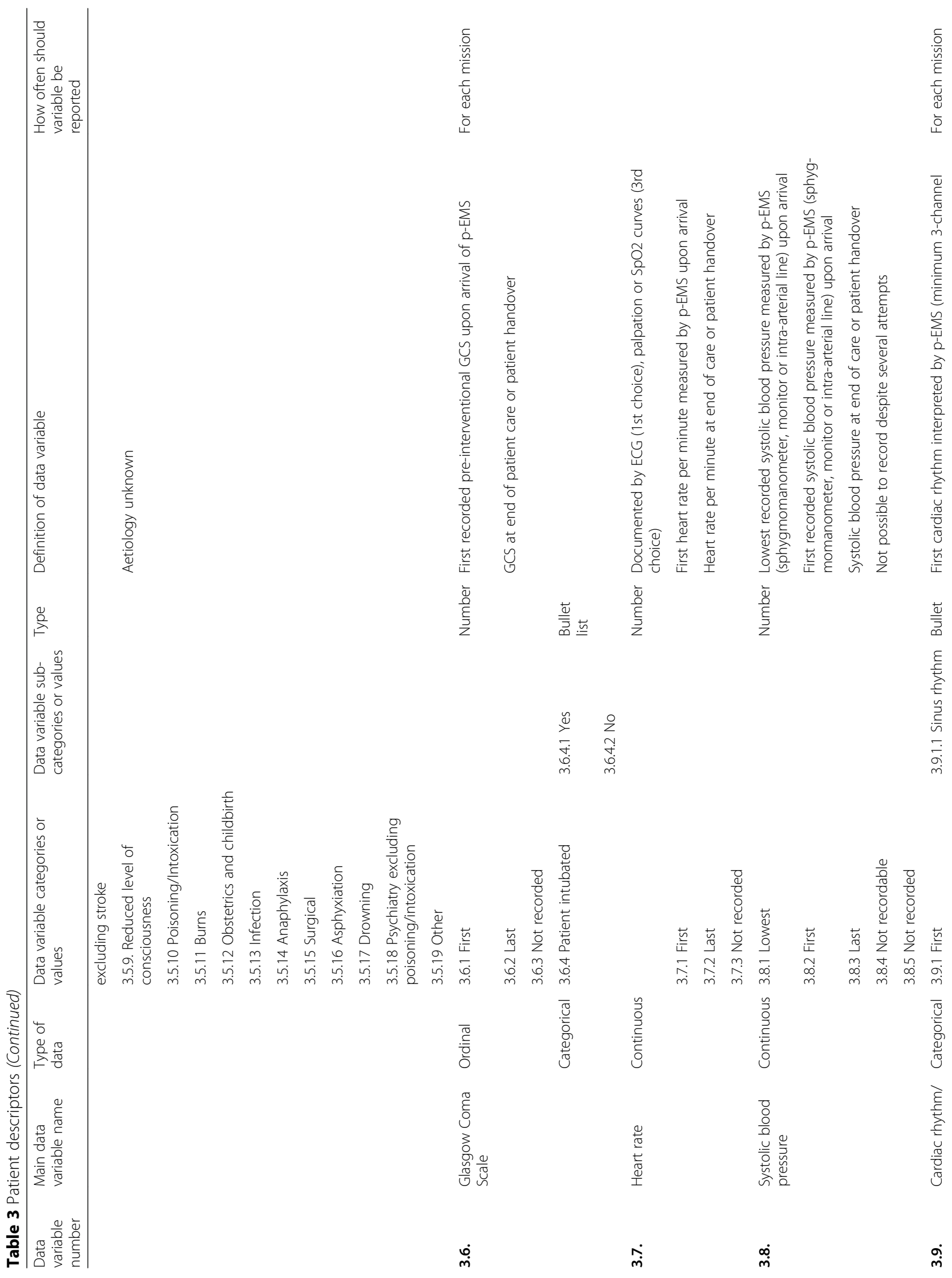




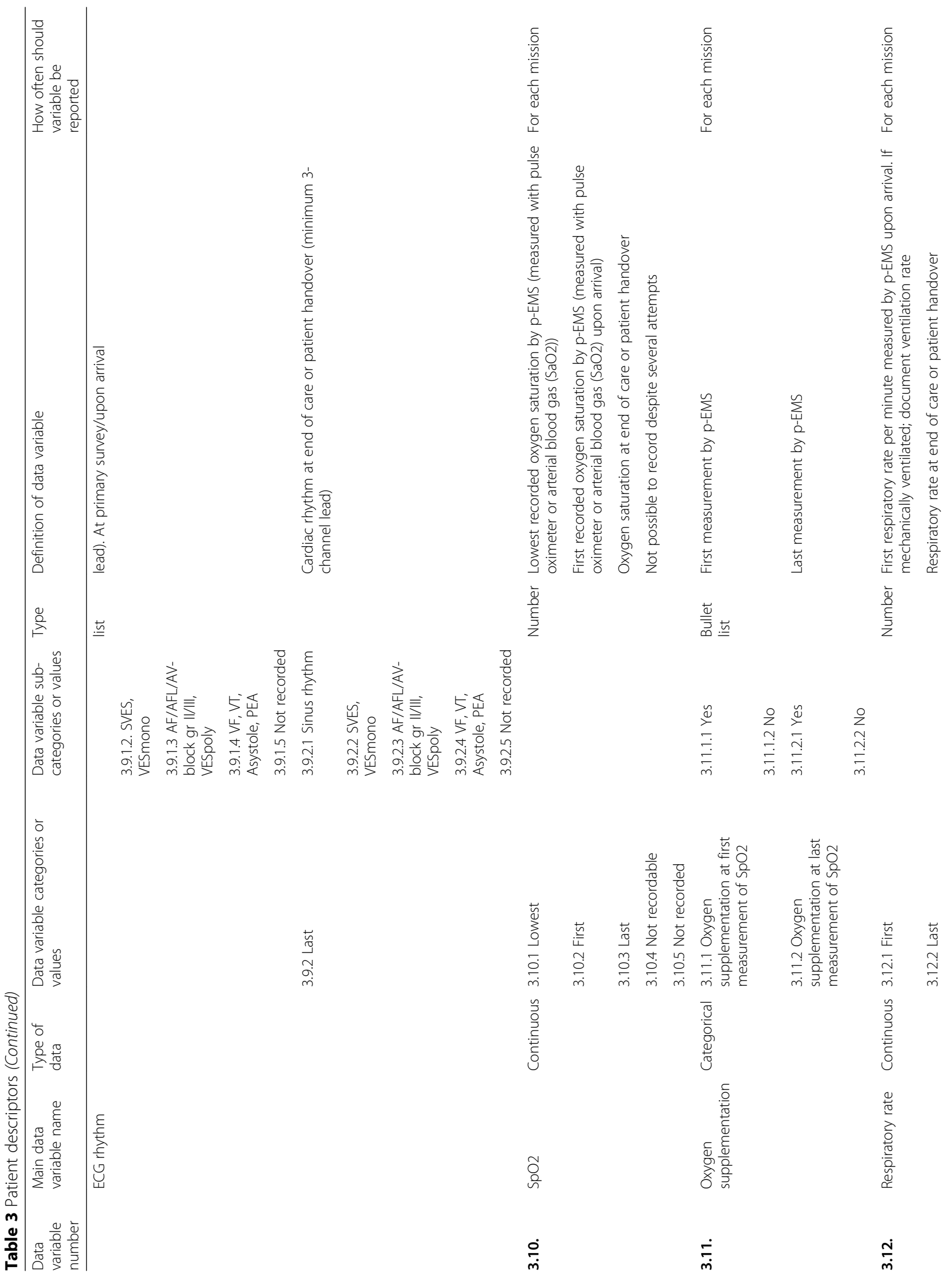




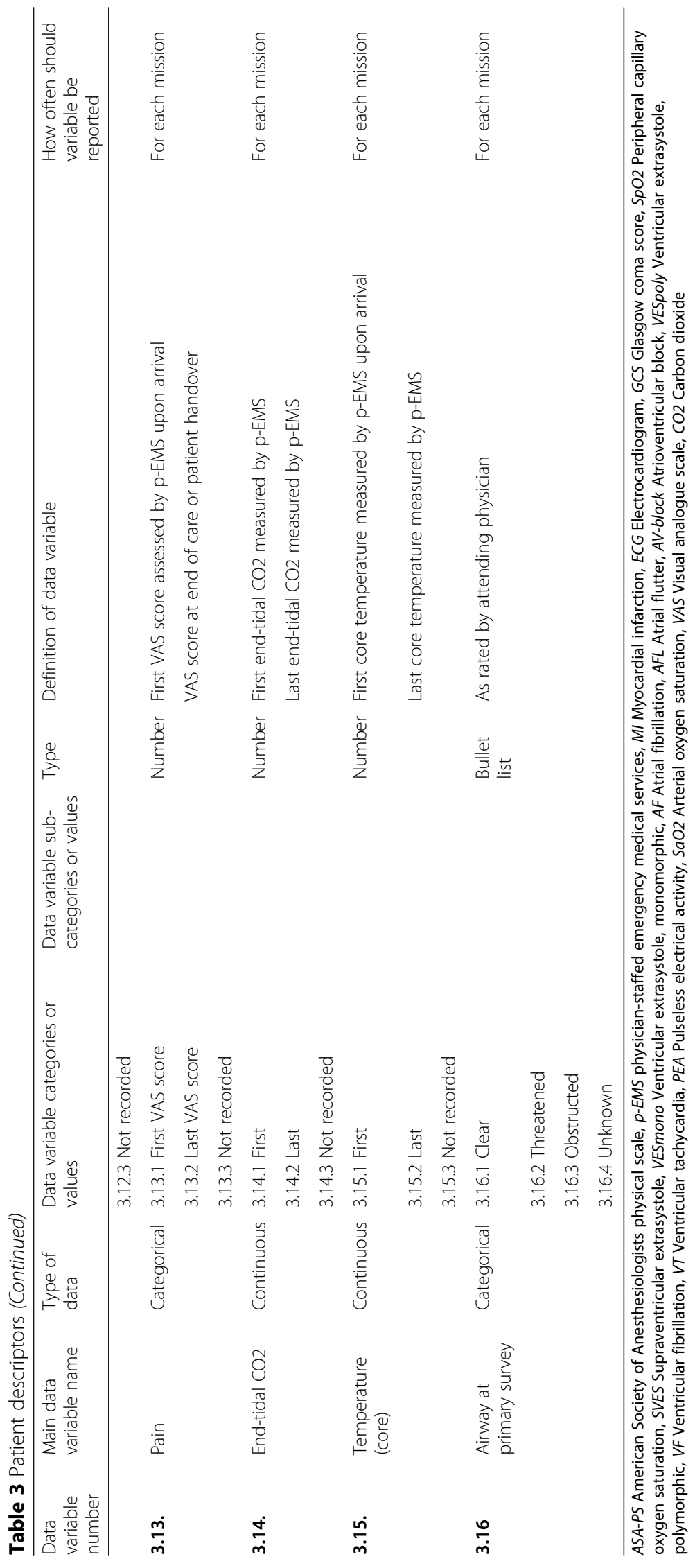




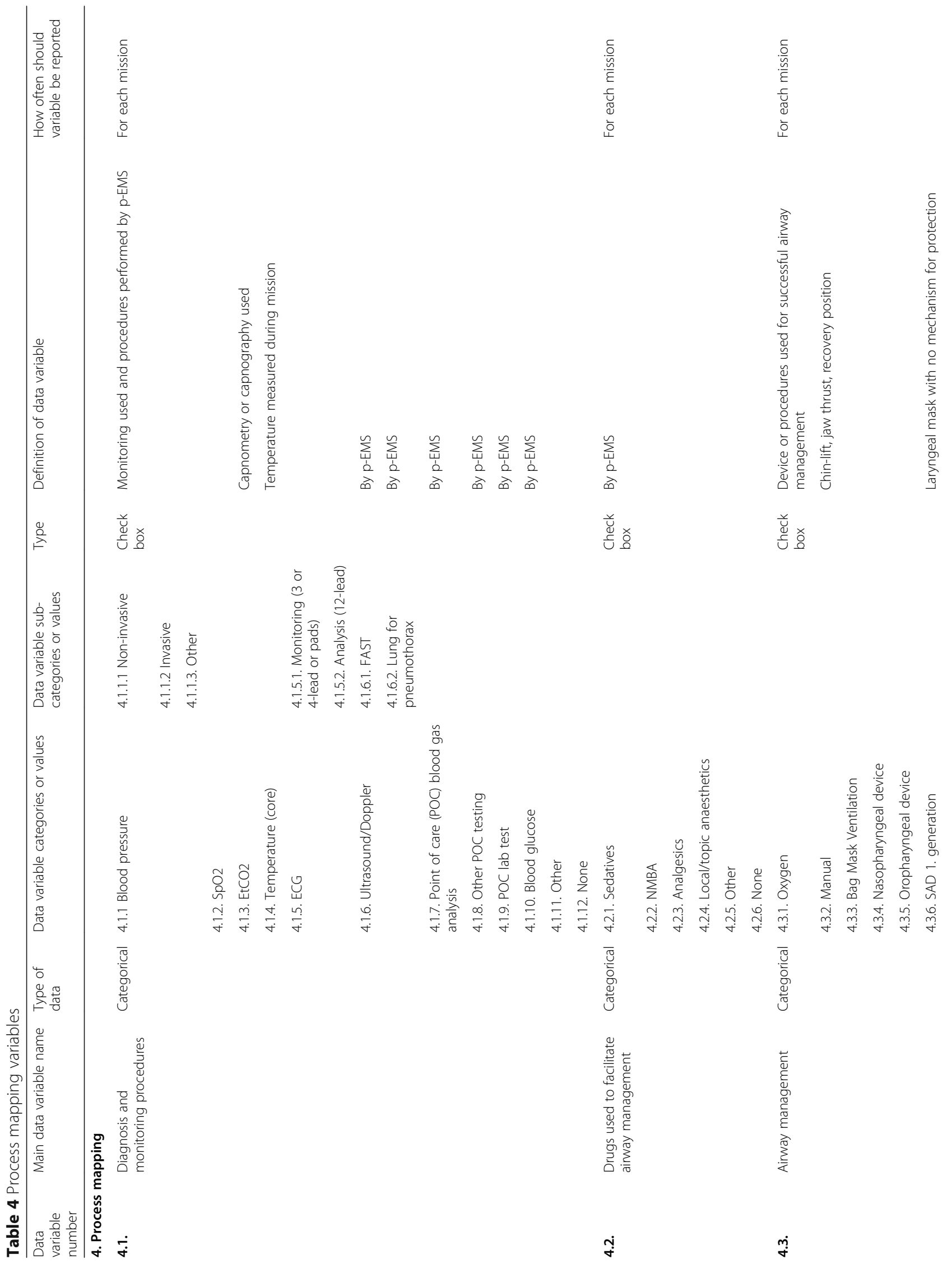




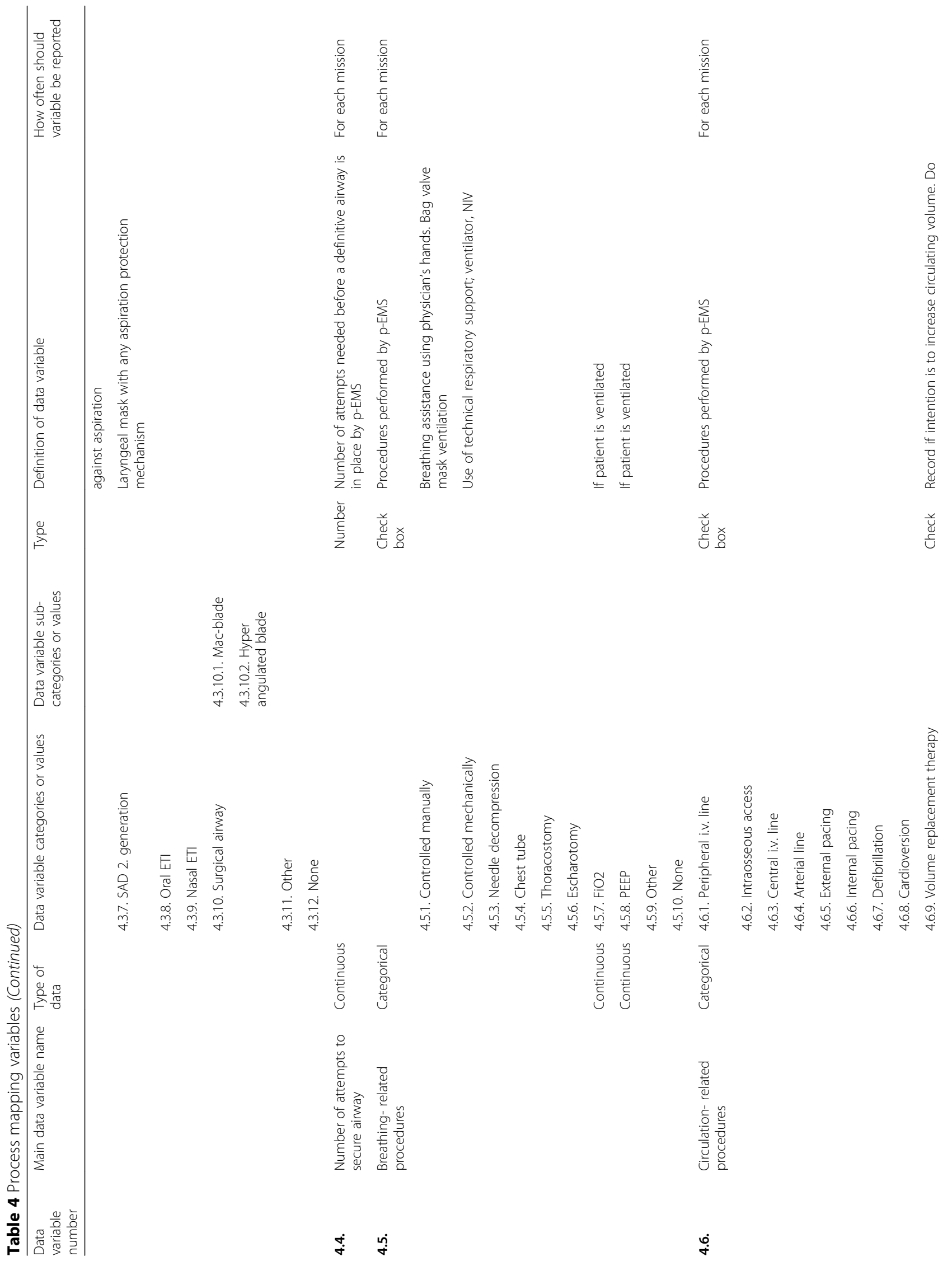









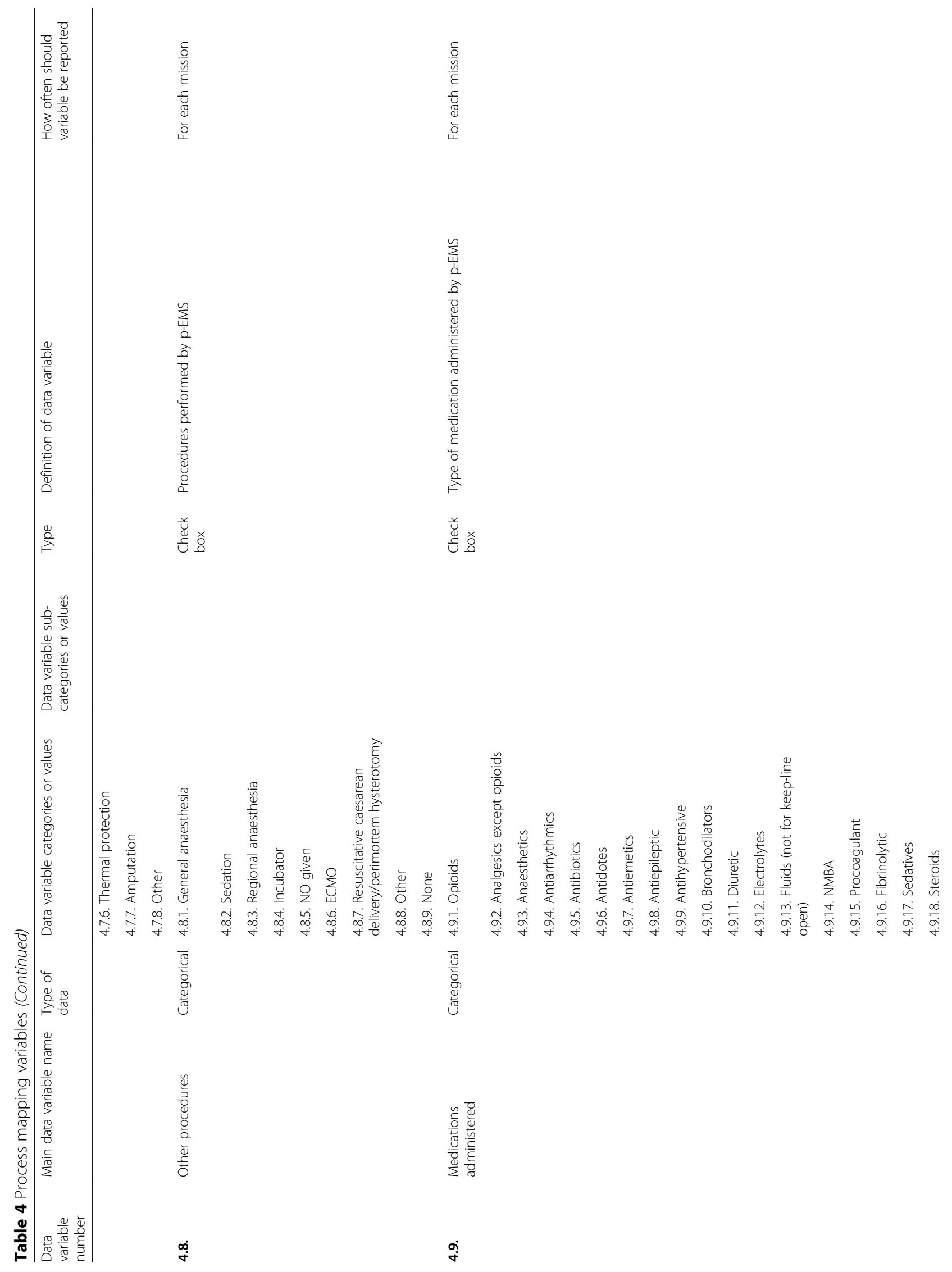




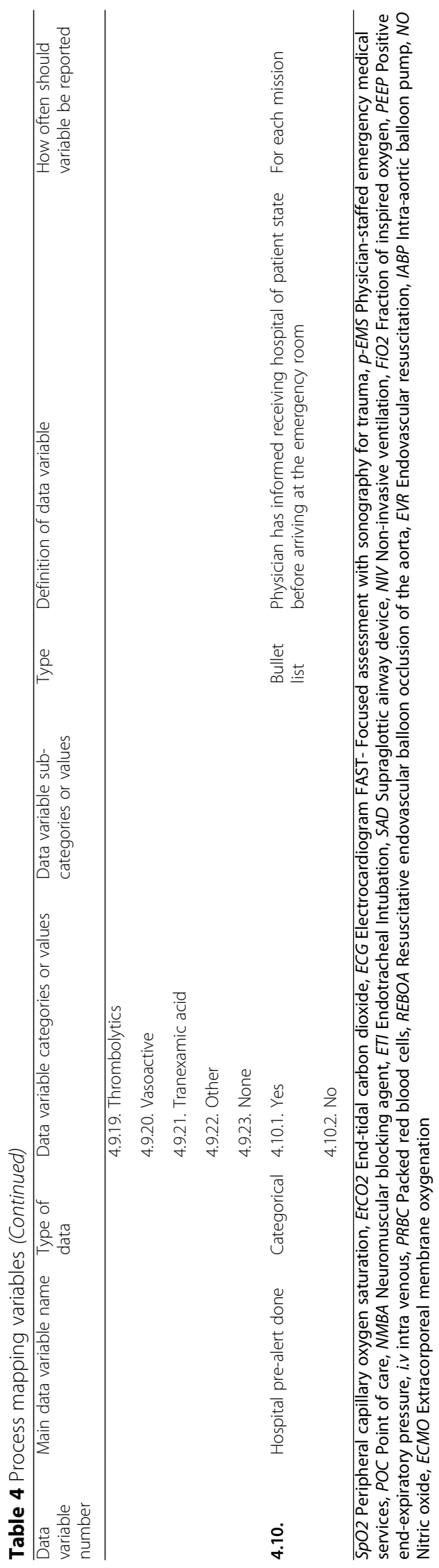




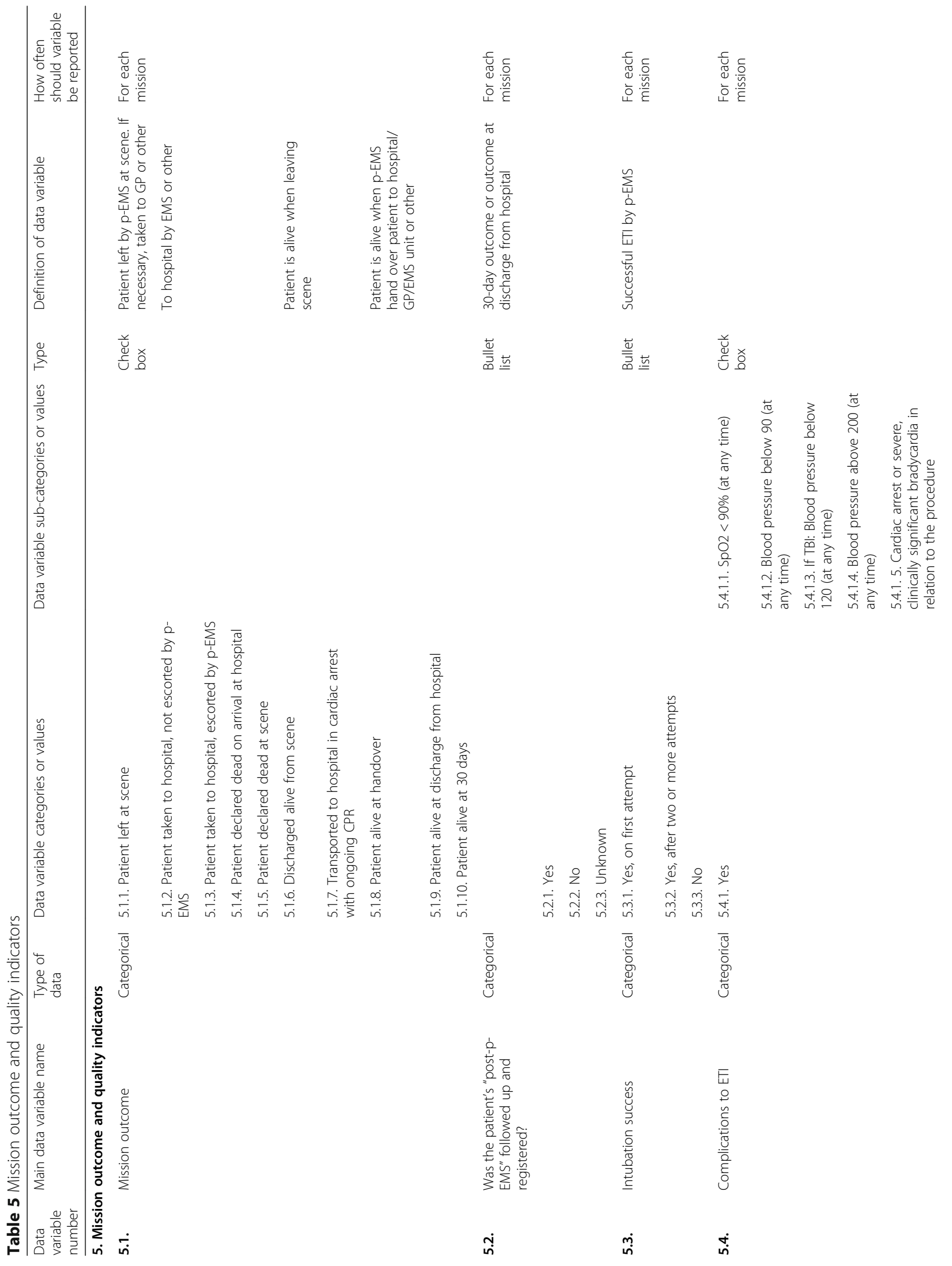




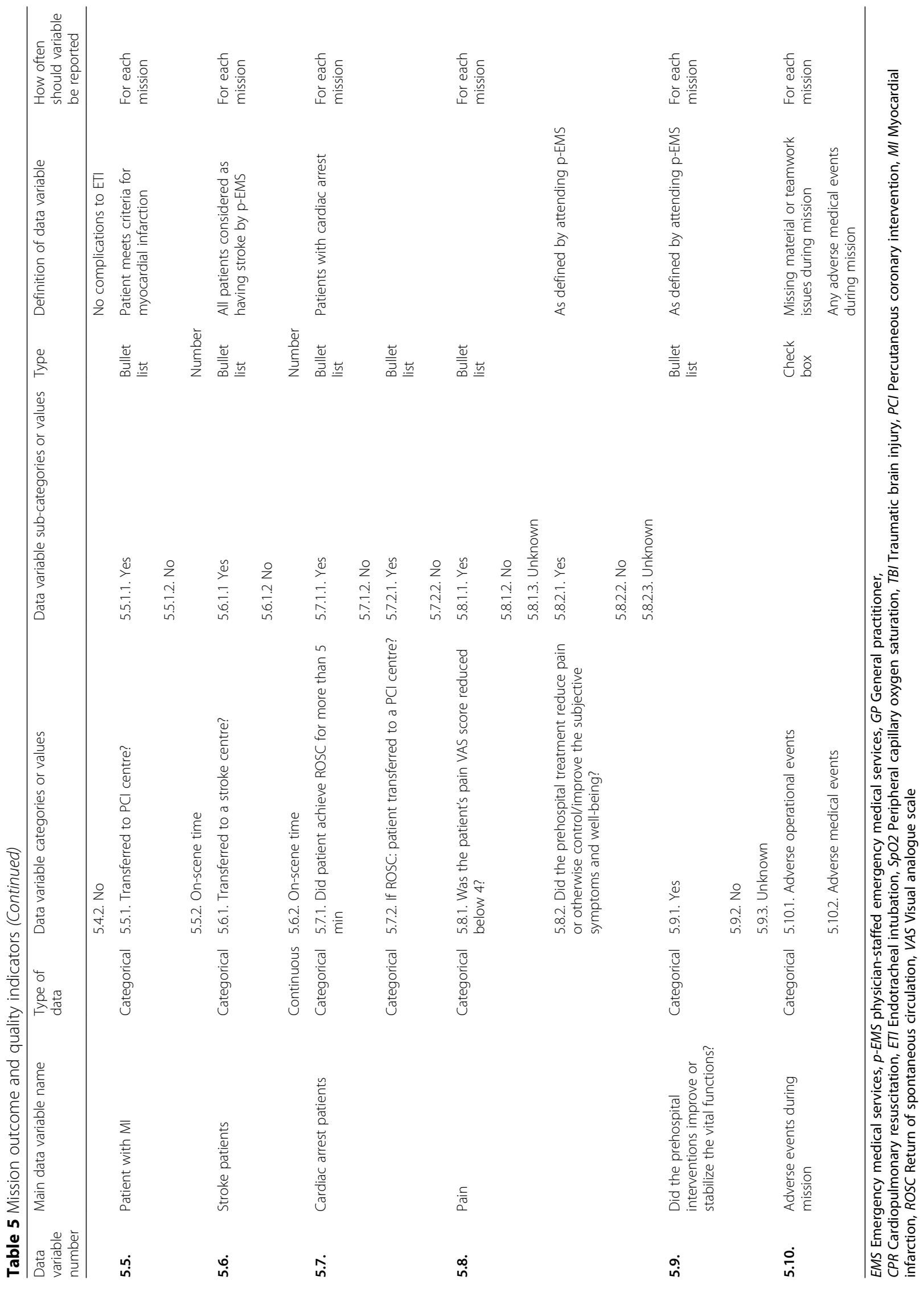


The experts recommend an event-specific long-term outcome measure to be included on a regular basis. The feasibility of capturing this variable as part of a standardized documentation in the $\mathrm{p}$-EMS population remains to be determined.

\section{General discussion}

Several consensus-based templates for reporting in EMS and p-EMS have been created (e.g., trauma, airway handling and cardiac arrest) $[14,15,26,36]$, and studies have proven that data collection according to such templates are feasible $[12,16,37]$. However, to increase the relevance of templates, variables should be coordinated. Of 26 variables in the template on quality indicators in p-EMS [35], five are identical to variables in the current template, six can easily be calculated and three are partially similar. Thus, little extra effort is required to document according to both templates. We believe that the coordination of variables and linking of templates will add value by reducing workload and increasing data capture, thereby facilitating future p-EMS research.

P-EMS are constantly developing, with new diagnostic and therapeutic options available, e.g. pre-hospital blood products, Tranexamic acid, extracorporeal membrane oxygenation (ECMO), thoracotomy and endovascular resuscitation on-scene. To capture these important trends, templates need to be updated regularly. Additionally, the variables shown to be not feasible to document should either be changed or removed. Physiological variables are often reported to be the most often missing variables [38, 39]. In the original template we found the feasibility of collecting physiological data to be good [16], and these variables were not substantially changed in the updated template. Thus, we expect feasibility to be good for physiological variables in the updated template as well.

To be able to compare outcomes, data must be unambiguously defined [26]. A data dictionary with precise definitions will be created for the present template. Furthermore, when implementing the template, it is important to ensure that all requested data are collected. Each service is free to choose whatever supplementary variables it wants, but all core variables should be captured by default, thereby facilitating future research.

Physician-staffed services are more expensive compared to ordinary EMS services making it a limited resource. This emphasize our obligation to use the service for the right patients. Therefore, we continually should strive to identify patients where p-EMS has an additional effect.

To provide a tool for collection of high-quality data is only a first step towards the improvement of p-EMS research. The next step is implementation, which is pivotal for template success. Aiming to increase awareness of the template, we invited experts from all over Europe to participate in its development. We believe this may facilitate implementation. Furthermore, to increase the implementation rate of the template, targeted efforts, such as involvement of stakeholders and highlighting the possibilities which lies within template data research, must be initiated.

Registries (e.g. for trauma and cardiac arrest) have facilitated a large amount of research [14, 40, 41]. In pEMS there is currently no joint register and each national service manages its own data. Furthermore, data are often registered on paper and later converted to digital format. Automated data capture from monitors and updated digitized data catchment tools could allow for complete template data to be imported directly into a common registry. This would provide a substantial opportunity for joint research. If such a registry could also link template data to outcomes and standardized coding systems for process and outcome issues, we may be able to assess e.g. for which patients p-EMS are useful, which procedures should be performed out-of-hospital and which procedures should not. However, the ethical and legal requirements of data sharing for research purposes (e.g. General Data Protection Regulation (GDPR)) must be taken into account and a substantial work to adhere to the current regulations are needed to succeed.

In the present study, we applied a Delphi method. This approach is in contrast with the Nominal Group Technique (NGT) that was used in the development of the original template. The classic Delphi method applies questionnaires with e-mails whereas the NGT involves a physical meeting with experts to reach a consensus [42]. The methods can also be combined into a modified NGT that starts with a Delphi process and ends with a physical meeting as a final step before consensus. Because this is an update of an existing template, we considered a physical meeting to be unnecessary. Furthermore, we wanted to ensure anonymity of the experts to prevent authors from favouring certain responses.

Reaching agreement is fundamental in Delphi studies, but a commonly accepted definition of consensus is absent [43]. In the present study we defined consensus as variables rated $\geq 4$ (on a scale from 1 to 5 ) by $>70 \%$ of experts. We consider this a transparent and systematic method for reaching a consensus.

\section{Limitations}

The recruitment of experts is prone to selection bias. For recruitment we used a set of predefined criteria and recruited experts from the EUPHOREA network consisting of representatives from p-EMS throughout central Europe, UK and Scandinavia. The low number of participants (9-11 physicians) may have introduced a selection bias. However, we managed to recruit a representative cohort of p-EMS physicians representing a broad range of European p-EMS. The physician-staffed services 
represented in the expert group are amongst the most active services in Europe and we believe this ensures generalizability of the results and that the effect of potential selection bias is minimized. By keeping proposals anonymous, we have avoided the effect of favouring proposals from certain experts.

\section{Conclusions}

Using a Delphi method, we have updated and revised the template for reporting in p-EMS. We recommend implementing the dataset for standard reporting in $\mathrm{p}$ EMS.

\begin{abstract}
Abbreviations
AF: Atrial fibrillation; AFL: Atrial flutter; ASA-PS: The American Society of Anesthesiologists Physical Status; AV-block: Atrioventricular block;

CO2: Carbon dioxide; CPR: Cardiopulmonary resuscitation; DASH1a: Definitive airway sans hypoxia/hypotension on first attempt; ECG: Electrocardiogram; ECMO: Extracorporeal membrane oxygenation; EMCC: Emergency medical communication centre; EMS: Emergency medical services; EtCO2: End-tidal carbon dioxide; ETI: Endotracheal Intubation; EUPHOREA: The European Prehospital Research Alliance; EVR: Endovascular resuscitation; FAST: Focused assessment with sonography for trauma; FiO2: Fraction of inspired oxygen; GCS: Glasgow coma score; GP: General practitioner; I.v.: Intra venous; IABP: Intra-aortic balloon pump; MI: Myocardial infarction; NAAF: Norwegian Air Ambulance Foundation; NACA score: National Advisory Committee for Aeronautics score; NGT: Nominal group technique; NIV: Non-invasive ventilation; NMBA: Neuromuscular blocking agent; NO: Nitric oxide; PCI: Percutaneous coronary intervention; PEA: Pulseless electrical activity; PEEP: Positive end-expiratory pressure; P-EMS: Physician-staffed emergency medical services; POC: Point of care; PRBC: Packed red blood cells; REBOA: Resuscitative endovascular balloon occlusion of the aorta; ROSC: Return of spontaneous circulation; SAD: Supraglottic airway device; SaO2: Arterial oxygen saturation; SAR: Search and rescue; SBP: Systolic blood pressure; SpO2: Peripheral capillary oxygen saturation; SRQR: the Standards for Reporting Qualitative Research; SVES: Supraventricular extrasystole; TBI: Traumatic brain injury; VAS: Visual analogue scale; VESmono: Ventricular extrasystole, monomorphic; VESpoly: Ventricular extrasystole, polymorphic; VF: Ventricular fibrillation; VT: Ventricular tachycardia
\end{abstract}

\section{Acknowledgements}

The authors would like to thank Kirsti Strømmen Holm for the excellent help with communication with the experts and anonymizing the answers. We also thank the donors of the Norwegian Air Ambulance Foundation who by their contributions funded this study and made this project possible. We are sincerely grateful for the contributions from the p-EMS Template Collaborating Group who made this study possible.

The P-EMS Template Collaborating Group: Bjørn Hossfeld (Germany), Ivo Breitenmoser (Switzerland), Mohyudin Dingle (UK), Attila Eröss (Hungary), Francisco Gallego (Spain), Peter Hilbert-Carius (Germany), Jo Kramer-Johansen (Norway), Jouni Kurola (Finland), Leif Rognås (Denmark), Patrick Schober (The Netherlands) and Ákos Soti (Hungary).

\section{Authors' contributions}

All authors (KT, AJK, KGR and MR) conceived the idea and participated in designing the study. KT analysed the data, AJK, KGR and MR supervised the analysis. All the collaborators participated in the Delphi process and all collaborators and all authors approved the final version of the template. All authors contributed to writing the manuscript and all authors have approved the final version of the manuscript.

\section{Funding}

The Norwegian Air Ambulance Foundation (NAAF) funded this project. However, the NAAF had no role in study design, data collection, analysis, writing or submitting to publication. The collaborators received no financial support for their participation in this study.

\section{Availability of data and materials}

The datasets used and/or analysed during the current study are available from the corresponding author on reasonable request.

\section{Ethics approval and consent to participate}

The Regional Ethics Committee (REK 2017/2498) considered the study protocol and concluded that no ethical approval was required. The Privacy Ombudsman (NSD 58762) considered the project not to include personal information, thereby exempting the duty of notification according to the European Union (EU) General Data Protection Regulation (GDPR).

\section{Consent for publication}

Not applicable.

\section{Competing interests}

The authors declare that they have no competing interests.

\section{Author details}

'Department of Research, The Norwegian Air Ambulance Foundation, Post box 414, Sentrum, N-0103, Oslo, Norway. ${ }^{2}$ Department of Anaesthesiology and Intensive Care, Stavanger University Hospital, Stavanger, Norway. ${ }^{3}$ Faculty of Health Sciences, University of Stavanger, Stavanger, Norway. ${ }^{4}$ Department of Emergency Medicine and Pre-Hospital Services, St. Olavs Hospital, Trondheim, Norway. ${ }^{5}$ Department of Anaesthesiology, Vestfold, Hospital Trust, Tønsberg, Norway. ${ }^{6}$ Norwegian Trauma Registry, Oslo University Hospital, Oslo, Norway. ${ }^{7}$ Pre-hospital Division, Air Ambulance Department, Oslo University Hospital, Oslo, Norway.

Received: 16 January 2020 Accepted: 2 March 2020

Published online: 03 April 2020

\section{References}

1. Den Hartog D, Romeo J, Ringburg AN, Verhofstad MH, Van Lieshout EM. Survival benefit of physician-staffed helicopter emergency medical services (HEMS) assistance for severely injured patients. Injury. 2015;46:1281-6.

2. Andruszkow H, Lefering R, Frink M, Mommsen P, Zeckey C, Rahe K, Krettek C, Hildebrand F. Survival benefit of helicopter emergency medical services compared to ground emergency medical services in traumatized patients. Crit Care. 2013;17:R124.

3. Frankema SP, Ringburg AN, Steyerberg EW, Edwards MJ, Schipper IB, van Vugt AB. Beneficial effect of helicopter emergency medical services on survival of severely injured patients. Br J Surg. 2004;91:1520-6.

4. Giannakopoulos GF, Kolodzinskyi MN, Christiaans HM, Boer C, de Lange-de Klerk ES, Zuidema WP, Bloemers FW, Bakker FC. Helicopter emergency medical services save lives: outcome in a cohort of 1073 polytraumatized patients. Eur J Emerg Med. 2013;20:79-85.

5. Ringburg AN, Thomas SH, Steyerberg EW, van Lieshout EM, Patka P, Schipper IB. Lives saved by helicopter emergency medical services: an overview of literature. Air Med J. 2009;28:298-302.

6. Peters J, van Wageningen B, Hendriks I, Eijk R, Edwards M, Hoogerwerf $N$, Biert J. First-pass intubation success rate during rapid sequence induction of prehospital anaesthesia by physicians versus paramedics. Eur J Emerg Med. 2015;22:391-4.

7. Kruger AJ, Lockey D, Kurola J, Di Bartolomeo S, Castren M, Mikkelsen S, Lossius HM. A consensus-based template for documenting and reporting in physician-staffed pre-hospital services. Scand J Trauma Resusc Emerg Med. 2011;19:71.

8. Popal Z, Bossers SM, Terra M, Schober P, de Leeuw MA, Bloemers FW, Giannakopoulos GF. Effect of physician-staffed emergency medical services (P-EMS) on the outcome of patients with severe traumatic brain injury: a review of the literature. Prehosp Emerg Care. 2019;23:730-9.

9. Fevang E, Lockey D, Thompson J, Lossius HM. The top five research priorities in physician-provided pre-hospital critical care: a consensus report from a European research collaboration. Scand I Trauma Resusc Emerg Med. 2011;19:57.

10. Engel DC, Mikocka-Walus A, Cameron PA, Maegele M. Pre-hospital and inhospital parameters and outcomes in patients with traumatic brain injury: a comparison between German and Australian trauma registries. Injury. 2010; 41:901-6.

11. Lossius HM, Kruger AJ, Ringdal KG, Sollid SJ, Lockey DJ. Developing templates for uniform data documentation and reporting in critical care 
using a modified nominal group technique. Scand J Trauma Resusc Emerg Med. 2013;21:80.

12. Ringdal KG, Lossius HM, Jones JM, Lauritsen JM, Coats TJ, Palmer CS, Lefering R, Di Bartolomeo S, Dries DJ, Soreide K. Collecting core data in severely injured patients using a consensus trauma template: an international multicentre study. Crit Care. 2011;15(R237).

13. Engel DC. Standardizing data collection in severe trauma: call for linking up. Crit Care. 2012;16:105.

14. Perkins GD, Jacobs IG, Nadkarni VM, Berg RA, Bhanji F, Biarent D, Bossaert LL, Brett SJ, Chamberlain D, de Caen AR, et al. Cardiac arrest and cardiopulmonary resuscitation outcome reports: update of the Utstein Resuscitation Registry Templates for Out-of-Hospital Cardiac Arrest: a statement for healthcare professionals from a task force of the International Liaison Committee on Resuscitation (American Heart Association, European Resuscitation Council, Australian and New Zealand Council on Resuscitation, Heart and Stroke Foundation of Canada, InterAmerican Heart Foundation, Resuscitation Council of Southern Africa, Resuscitation Council of Asia); and the American Heart Association Emergency Cardiovascular Care Committee and the Council on Cardiopulmonary, Critical Care, Perioperative and Resuscitation. Circulation. 2015;132:1286-300.

15. Sunde GA, Kottmann A, Heltne JK, Sandberg M, Gellerfors M, Kruger A, Lockey D, Sollid SJM. Standardised data reporting from pre-hospital advanced airway management - a nominal group technique update of the Utstein-style airway template. Scand I Trauma Resusc Emerg Med. 2018;26:46.

16. Tonsager K, Rehn M, Ringdal KG, Lossius HM, Virkkunen I, Osteras O, Roislien J, Kruger AJ. Collecting core data in physician-staffed pre-hospital helicopter emergency medical services using a consensus-based template: international multicentre feasibility study in Finland and Norway. BMC Health Serv Res. 2019;19:151.

17. Kruger AJ, Skogvoll E, Castren M, Kurola J, Lossius HM. Scandinavian prehospital physician-manned emergency medical services--same concept across borders? Resuscitation. 2010;81:427-33.

18. Murphy A, Wakai A, Walsh C, Cummins F, O'Sullivan R. Development of key performance indicators for prehospital emergency care. Emerg Med J. 2016; 33:286-92.

19. Schwartz HP, Bigham MT, Schoettker PJ, Meyer K, Trautman MS, Insoft RM. Quality metrics in neonatal and pediatric critical care transport: a National Delphi Project. Pediatr Crit Care Med. 2015;16:711-7.

20. O'Brien BC, Harris IB, Beckman TJ, Reed DA, Cook DA. Standards for reporting qualitative research: a synthesis of recommendations. Acad Med. 2014;89:1245-51

21. Di Bartolomeo S, Gava P, Truhlar A, Sandberg M. Cross-sectional investigation of HEMS activities in Europe: a feasibility study. ScientificWorldJournal. 2014;2014:201570.

22. Mould-Millman NK, Dixon JM, Sefa N, Yancey A, Hollong BG, Hagahmed M, Ginde AA, Wallis LA. The state of emergency medical services (EMS) Systems in Africa. Prehosp Disast Med. 2017;32:273-83.

23. Ong ME, Cho J, Ma MH, Tanaka H, Nishiuchi T, Al Sakaf O, Abdul Karim S, Khunkhlai N, Atilla R, Lin CH, et al. Comparison of emergency medical services systems in the pan-Asian resuscitation outcomes study countries: report from a literature review and survey. Emerg Med Australas. 2013;25: 55-63.

24. Roudsari BS, Nathens AB, Cameron P, Civil I, Gruen RL, Koepsell TD, Lecky FE, Lefering RL, Liberman M, Mock CN, et al. International comparison of prehospital trauma care systems. Injury. 2007;38:993-1000.

25. Dick WF, Baskett PJ. Recommendations for uniform reporting of data following major trauma--the Utstein style. A report of a working party of the international trauma Anaesthesia and critical care society (ITACCS). Resuscitation. 1999;42:81-100

26. Ringdal KG, Coats TJ, Lefering R, Di Bartolomeo S, Steen PA, Roise O, Handolin L, Lossius HM. The Utstein template for uniform reporting of data following major trauma: a joint revision by SCANTEM, TARN, DGU-TR and RITG. Scand J Trauma Resusc Emerg Med. 2008;16:7.

27. Tønsager K, Rehn M, Krüger AJ, Røislien J, Ringdal KG. Kan luftambulanseleger skåre ASA pre-hospitalt? In Høstmøtet 2017. Oslo: NAF forum; 2017:46.

28. Hov MR, Zakariassen E, Lindner T, Nome T, Bache KG, Roislien J, Gleditsch J, Solyga V, Russell D, Lund CG. Interpretation of brain CT scans in the field by critical care physicians in a Mobile stroke unit. J Neuroimaging. 2018;28:106-11.
29. Walter S, Kostopoulos P, Haass A, Keller I, Lesmeister M, Schlechtriemen T, Roth C, Papanagiotou P, Grunwald I, Schumacher H, et al. Diagnosis and treatment of patients with stroke in a mobile stroke unit versus in hospital: a randomised controlled trial. Lancet Neurol. 2012;11:397-404.

30. Bergmann I, Buttner B, Teut E, Jacobshagen C, Hinz J, Quintel M, Mansur A, Roessler M. Pre-hospital transthoracic echocardiography for early identification of non-ST-elevation myocardial infarction in patients with acute coronary syndrome. Crit Care. 2018;22:29.

31. Reid BO, Rehn M, Uleberg O, Kruger AJ. Physician-provided prehospital critical care, effect on patient physiology dynamics and on-scene time. Eur J Emerg Med. 2018;25:114-9.

32. Aiolfi A, Benjamin E, Khor D, Inaba K, Lam L, Demetriades D. Brain Trauma Foundation guidelines for intracranial pressure monitoring: compliance and effect on outcome. World J Surg. 2017;41:1543-9.

33. Scholten AC, Berben SA, Westmaas AH, van Grunsven PM, de Vaal ET, Rood PP, Hoogerwerf N, Doggen CJ, Schoonhoven L. Pain management in trauma patients in (pre) hospital based emergency care: current practice versus new guideline. Injury. 2015;46:798-806.

34. Wewers ME, Lowe NK. A critical review of visual analogue scales in the measurement of clinical phenomena. Res Nurs Health. 1990;13:227-36.

35. Haugland $H$, Rehn M, Klepstad P, Kruger A. Developing quality indicators for physician-staffed emergency medical services: a consensus process. Scand J Trauma Resusc Emerg Med. 2017;25:14.

36. Cummins RO, Chamberlain DA, Abramson NS, Allen M, Baskett PJ, Becker L, Bossaert L, Delooz HH, Dick WF, Eisenberg MS, et al. Recommended guidelines for uniform reporting of data from out-of-hospital cardiac arrest: the Utstein style. A statement for health professionals from a task force of the American Heart Association, the European resuscitation council, the Heart and Stroke Foundation of Canada, and the Australian resuscitation council. Circulation. 1991;84:960-75.

37. Okubo M, Komukai S, Izawa J, Gibo K, Kiyohara K, Matsuyama T, Kiguchi T, Iwami T, Callaway CW, Kitamura T. Prehospital advanced airway management for paediatric patients with out-of-hospital cardiac arrest: A nationwide cohort study. Resuscitation. 2019;145:175-84.

38. Laudermilch DJ, Schiff MA, Nathens AB, Rosengart MR. Lack of emergency medical services documentation is associated with poor patient outcomes: a validation of audit filters for prehospital trauma care. J Am Coll Surg. 2010; 210:220-7.

39. O'Reilly GM, Cameron PA, Jolley DJ. Which patients have missing data? An analysis of missingness in a trauma registry. Injury. 2012;43:1917-23.

40. O'Reilly GM, Joshipura M, Cameron PA, Gruen R. Trauma registries in developing countries: a review of the published experience. Injury. 2013;44: 713-21.

41. Shivasabesan G, Mitra B, O'Reilly GM. Missing data in trauma registries: a systematic review. Injury. 2018;49:1641-7.

42. McMillan SS, King M, Tully MP. How to use the nominal group and Delphi techniques. Int J Clin Pharm. 2016;38:655-62.

43. Diamond IR, Grant RC, Feldman BM, Pencharz PB, Ling SC, Moore AM, Wales PW. Defining consensus: a systematic review recommends methodologic criteria for reporting of Delphi studies. J Clin Epidemiol. 2014;67:401-9.

\section{Publisher's Note}

Springer Nature remains neutral with regard to jurisdictional claims in published maps and institutional affiliations.

Ready to submit your research? Choose BMC and benefit from:

- fast, convenient online submission

- thorough peer review by experienced researchers in your field

- rapid publication on acceptance

- support for research data, including large and complex data types

- gold Open Access which fosters wider collaboration and increased citations

- maximum visibility for your research: over $100 \mathrm{M}$ website views per year

At BMC, research is always in progress.

Learn more biomedcentral.com/submissions 